\title{
ELABORATION OF THE 3D MODEL AND SURVEY OF THE POWER LINES USING DATA FROM AIRBORNE LASER SCANNING
}

\author{
Bogusława Kwoczyńska', Joanna Dobek
}

1 Department of Agricultural Land Surveying, Cadaster and Photogrammetry, University of Agriculture in Krakow, ul. Balicka 253 a, 30-198 Kraków, Poland, e-mail: rmkwoczy@cyf-kr.edu.pl

Received: 2016.06 .08 Accepted: 2016.07.26 Published: 2016.09.20

\begin{abstract}
One of the methods of obtaining highly accurate and current spatial data about the terrain, as well as objects situated on it, is laser scanning. LIDAR (Light Detection and Ranging) is among the most modern, dynamically developing technologies and reveals in surveying new capabilities that have been unachievable in a traditional way so far. The aim of the publication is to show the possibilities of using data from airborne laser scanning to perform the survey and visualization of the energy network, and also identification of hazards which the present network constitutes for the immediate environment using the TerraSolid software package. The survey was conducted for two independent sections of the power line, on the basis of two different clouds of points obtained from the airborne laser scanning. The first one had a density of 16 points $/ \mathrm{m}^{2}$, while the other $22 \mathrm{pts} / \mathrm{m}^{2}$. The project was created in an environment of MicroStation V8i software using special overlays - TerraScan and TerraModeler of Finnish TerraSolid Company. The use of the test clouds of different densities was intended to indicate an optimal density of the cloud of points, which allows carrying out a survey and visualization of the energy network based on data derived from airborne laser scanning. The publication presents on particular examples the procedure of vectorization and visualization of the power line and detection of objects within a dangerous distance from it. The possibility of using applied LIDAR data, meeting the industry requirements, to the survey of power lines has been also confirmed.
\end{abstract}

Keywords: airborne laser scanning, power lines, survey

\section{INTRODUCTION}

On 30 July 2010, The Head Office of Geodesy and Cartography (GUGiK) in consortium with the National Water Management Authority, Institute of Meteorology and Water Management - National Research Institute, Institute of Communication - National Research Institute and Government Security Centre started the project „IT System for the Protection of the Country from extraordinary dangers - ISOK". The aim of the ISOK project was to create a comprehensive IT system, together with the necessary georeference databases, in order to effectively notify and alert relevant institutions and population about dangers.
The key product obtained by GUGiK in the project ISOK were elevation data obtained in the airborne laser scanning technology, which served to develop hazard maps and flood risk maps and directly replenished the database of aerial and satellite imagery and orthophotomaps and digital terrain model of the state geodetic and cartographic resources (PZGIK). These data were processed in two standards.

As the result of the works carried out by GUGiK in years 2011-2015 elevation data in the technology of airborne laser scanning were acquired and processed for a total area of 287 $769 \mathrm{~km}^{2}$, what represents $92 \%$ of the country.

The first elevation data elaborated in the ISOK project were included into the state geodetic and 
cartographic resources early 2012. From the first days when they became available to the public, the end of 2015 data of the total area of 10.9 million $\mathrm{km}^{2}$ were made available within the framework of orders placed by 1366 unique users. With every year of availability of data from the project ISOK in PZGIK increases the number of orders for them executed by the Central Documentation Centre of Geodesic and Cartographic Documentation (CODGiK), at the end of 2015 it was globally 2649 (110 orders in 2012, 575 in 2013, 679 in 2014 and 1285 in 2015). Access to the elevation data of unprecedented accuracy caused, that they have been used in every sector of the economy, in the areas which were known only to a few specialists who knew the potential of the ALS data (ALS - Airborne Laser Scanning) at the beginning of the ISOK project [Andrzejewski 2016].

The most popular applications of the laser data include, among others:

- three-dimensional modeling of towns,

- designing the course of roads and monitoring them,

- design and maintenance of railway lines and objects associated with them,

- management of natural resources (forests),

- studies of flood hazard,

- monitoring of coastal zones,

- monitoring of water objects (dams, bridges),

- analysis of noise,

- determination of the range of telecommunication antennas,

- registration of high-voltage lines,

- monitoring of architectural objects.

Data from the airborne laser scanning are obtained for large areas, for which geodetic surveys and other methods involving direct presence in the field do not give satisfactory results. The best example of their use is surveying of power lines based on the software of the Finnish company Terrasolid.

Research on the use of laser scanning to record and survey of power lines have been carried out in Poland and all over the world for several years, as evidenced by the works [Figiel 2015, Gola 2015, McLaughlin 2006, Melzer and Briese 2004, Jwa et al. 2009, Liang et al. 2011, Sohn et al. 2012, Zhu and Hyyppa 2014].

The use of the terrestrial, mobile and airborne laser scanning in many scientific and research works allowed for identification of the advantages and disadvantages of each of these techniques [Bęcek et al. 2015, Bitenc et al. 2011, Gawronek and Mitka 2015, Dobek 2016, Tarek
2002, Mądrzyk 2015. Data obtained in this way and their accuracy allow to carry out a series of diagnostic analysis presented among others in following publications [Głowienka et al. 2015, Mikrut et al. 2012, Soni et al. 2014, Stereńczak 2009, Kim and Sohn 2010].

\section{THE TECHNIQUE OF AIRBORNE LASER SCANNING}

Laser scanning is based on a very fast determination of XYZ coordinates of the vast number of points by the laser measurement. The obtained ,point cloud” allows, after appropriate processing, generation of a three-dimensional model of the scanned object. The described cloud is not just a set of points that have coordinates $\mathrm{XYZ}$ - it is also the reflection intensity parameters; this information is often of higher demand. The product of scanning can be either the same point cloud as the final product and also after further processing plans, maps, drawings, digital models of the terrain, photorealistic models and 3D videos, visualizations, high-resolution panoramic photos, orthophotomaps and many others [Figiel 2015].

Rapid development of this technology allows the collection together with the coordinates XYZ, information on colors of measurement objects, what allows instantly obtaining colorized point cloud. Very common is also the integration of a scanner with a photographic camera, so that at the same time photographic documentation is collected, which can then easily be applied to the point cloud as a texture.

The undeniable advantages of scanning are:

- independence from lighting conditions (the ability to operate at night),

- a considerable independence from weather conditions,

- very high accuracy of the altitude measurement data,

- high speed of data collection (eg. $80 \mathrm{~km}$ of a railway line during two hours),

- a short time of deriving the end product and a relatively low cost,

- providing a huge amount of information about the terrain,

- easy integration of data with GIS.

But as any technology, it also has some limitations, and these are: 
- absorption of laser pulses by some surfaces (water, asphalt, tar),

- absorption of laser pulses by the thick clouds and fog,

- large volume of data sets.

Obtaining elevation data in the technology of airborne laser scanning within the ISOK project is an important step in creation of high resolution, uniform and available on a national scale spatial 3D data. The Head Office of Geodesy and Cartography recognizing the need for the continuation of completed activities undertaken in the ISOK already in the course of the project has undertaken action to determine the needs of users of spatial data 3D in terms of their expectations regarding further data acquisition in the technology of airborne laser scanning, their updating and acquisition of new data and making available network services based on these data [Andrzejewski 2016].

\section{THE USE OF LASER SCANNING IN ENERGY SECTOR}

In energy sector three-dimensional point cloud allows for a perfect representation of not only the geometry of poles but also of the elements such as: power lines, insulators, transformers and other technical equipment. Network and power lines monitoring minimizes the likelihood of failure and power outages caused by poor technical condition of equipment. Early diagnostics and risk analysis of a collision with vegetation or failure resulting from improper maintenance of line helps manage the energy network efficiently [Figiel 2015].

The analysis of power lines based on LIDAR data provides new, previously unknown possibilities. It is very important for users to increase efficiency by using appropriate software. Such a program is TerraSolid allowing for automation of the process of vectorization of the course of line, and also the poles modeling. Thanks to the tools of the TerraScan overlay accurate and editable vector files in a widely supported DGN format are obtained.

The survey of power lines takes into account all the guidelines contained in the standards: PN-EN 50341-1:2005/A1:2009, PN-EN 50341-3:2005/AC:2009 oraz PN-EN 503413-22:2010. They concern the overhead electric power lines above AC $45 \mathrm{kV}$ - general requirements and common specifications, as well as the set of normative national conditions (Polish version of EN 50341-3-22:2001). Similarly, standards PN-EN 50423-3:2005/AC:2009 concerning the overhead power lines above AC $1 \mathrm{kV}$ up to $45 \mathrm{kV}$ inclusive - the set of normative national conditions. Parameters of the execution of scanning and the requirements for further processing of laser data in the elaboration of power lines usually are specified in the technical specification or tender specification. Important information relate inter alia to the classification of points cloud, which should:

- include at least the following classes:

- ground,

- low vegetation,

- medium vegetation,

- high vegetation,

- buildings,

- infrastructure elements (roads, railways, pipelines, other power lines),

- waters,

- unclassified,

- noise,

- accuracy of point height measurement $\mathrm{Zm}_{\mathrm{h}} \leq$ $0,05 \mathrm{~m}$,

- accuracy of the measurement of horizontal coordinates: $\mathrm{X}, \mathrm{Ym}_{\mathrm{p}} \leq 0,10 \mathrm{~m}$,

- permissible error of points classifying below the $5 \%$,

- data format: .LAS 1.2,

- the scope of the study in the belt of at least +/$100 \mathrm{~m}$. from the axis line, and at least $100 \mathrm{~m}$. from the edge of the station,

- Coordinate Systems PUWG 1992.

Performing LIDAR method scanning for PSE, PGE and TAURON is carried out using, for example, the Riegl VQ-480i scanner, which is in the possession of, among others, MGGP Aero. The density of scanning for this scanner ranges from $20-100 \mathrm{pts} / \mathrm{m}^{2}$ depending on the customer and the aim of measurments. The survey of power lines is usually carried out with the density of about $25 \mathrm{pts} / \mathrm{m}^{2}$. The accuracy of the acquired spatial cloud: mean square error for the line is $0.02-0.05 \mathrm{~m}$ for $\mathrm{XY}, 0.04-0.08 \mathrm{~m}$ for $\mathrm{Z}$.

In the survey of power lines very often the integration of data from airborne and ground laser scanning is used. Using long-range laser scanner Riegl VZ-400 it is possible to measure not only supporting structures and foundations of overhead high-voltage lines but also cables, insulators, technical equipment and other items arising from the manner of conducting the line [21]. 
Using a laser scanner the measurement is made from each station in the "panorama 40 " mode, which means that the points are measured in a grid of $35 \times 35 \mathrm{~mm}$ for $50 \mathrm{~m}$ for a single scan. In practice the density of about $15 \mathrm{~mm}$ is obtained because each measured object is measured from several stations of the scanner. Measurement accuracy for a single point using Riegl VZ 400 scanner is in the horizontal plane about $0.003 \mathrm{~m}$ and in a vertical plane $0.003 \mathrm{~m} \mathrm{[20].}$

The advantage of this measurement technology is obtaining accurate and comprehensive spatial information about the object and its surroundings in a very short time. This enables monitoring of the technical status of the elements of power lines, checking the correct distance of the cables from the ground, brushes, tree branches and objects near the line.

\section{CHARACTERISTICS OF THE TEST OBJECTS}

In order to demonstrate the applicability of the technology of airborne laser scanning in surveying of power lines, two separate sections of high and low voltage power lines, the first with the length $2.23 \mathrm{~km}$, and the second $1.04 \mathrm{~km}$ have been involved in tests (Figure 1).

The survey was conducted on the basis of two different clouds of points obtained from the airborne laser scanning. The first one had a den- sity of 16 points $/ \mathrm{m}^{2}$, while the other $22 \mathrm{pts} / \mathrm{m}^{2}$. The cloud was obtained as a result of the corridor flight, from the low-level $(280 \mathrm{~m})$ and the lowest allowable flight speed in order to obtain high values of density of the resulting point cloud. The accuracy of the acquired spatial cloud: mean square error for the line is $0.02-0.05 \mathrm{~m}$ for $\mathrm{XY}$, $0.04-0.08 \mathrm{~m}$ for $\mathrm{Z}$. The project was created in an environment of MicroStation V8i software using special overlays - TerraScan and TerraModeler of Finnish TerraSolid Company. Less dense cloud of points included the power line, which consisted of 7 high voltage pylons. While, the dense cloud was obtained for two high-power lines (3 pylons) and low voltage line ( 8 poles) running next to each other (Figure 2).

\section{SURVEYING OF POWER LINES IN THE TERRASOLID SOFTWARE}

The very process of generating power lines in the TerraScan overlay is intuitive and reduced to a few simple steps. Processing the data using the most of the tools of the TerraScan overlay is possible after identifying classes of selected elements. The classification can be carried out automatically or manually (Figure $3)$. In practice, the two most commonly both solutions are used, because the automatic process requires control and correction of errors. Before starting the work, it is necessary to cre-

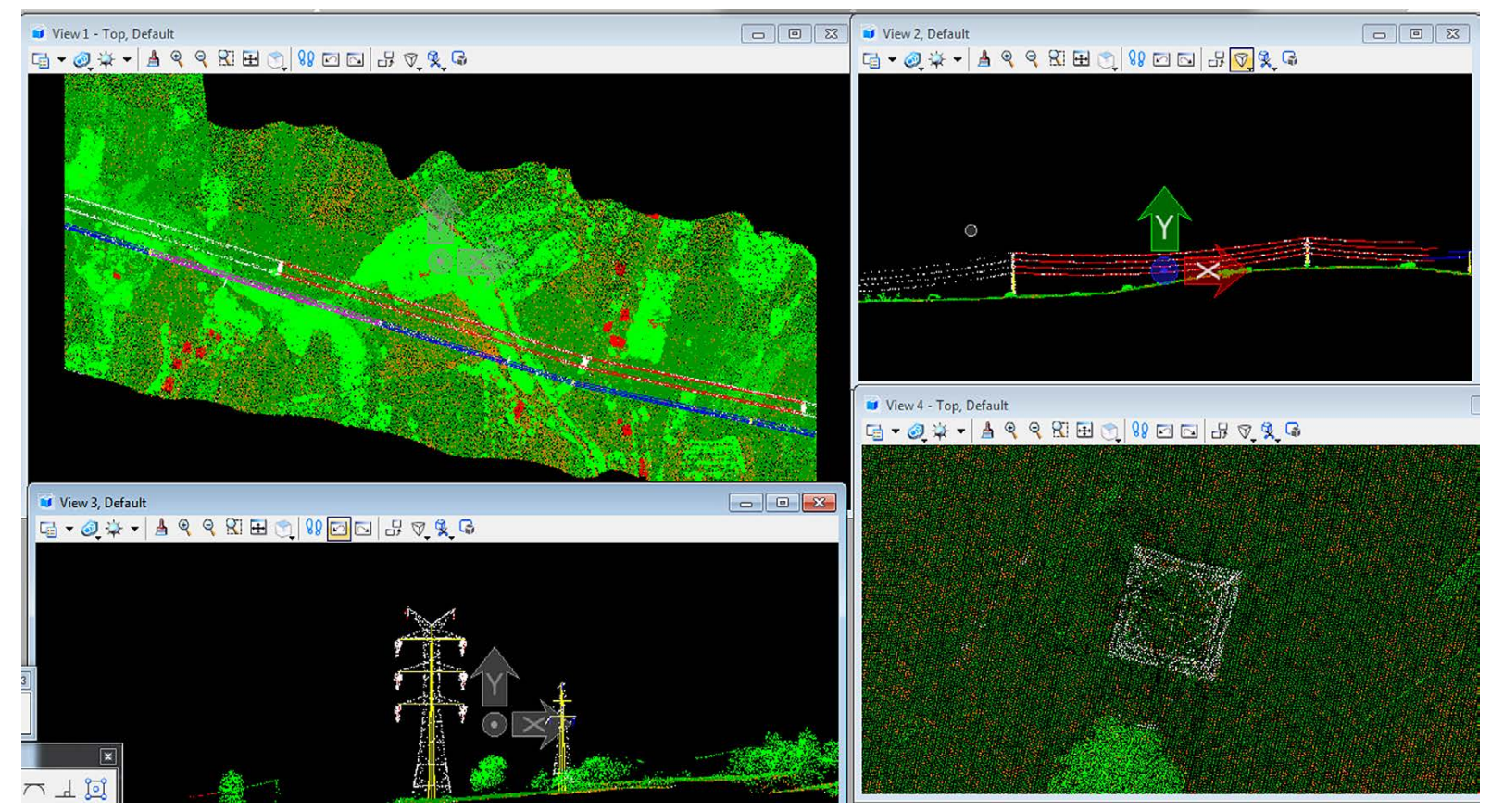

Figure 1. The cloud of points with marked power lines 
iview 4, Default

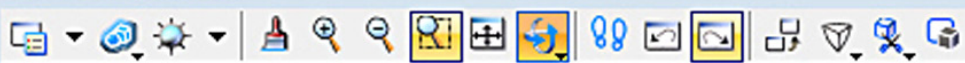

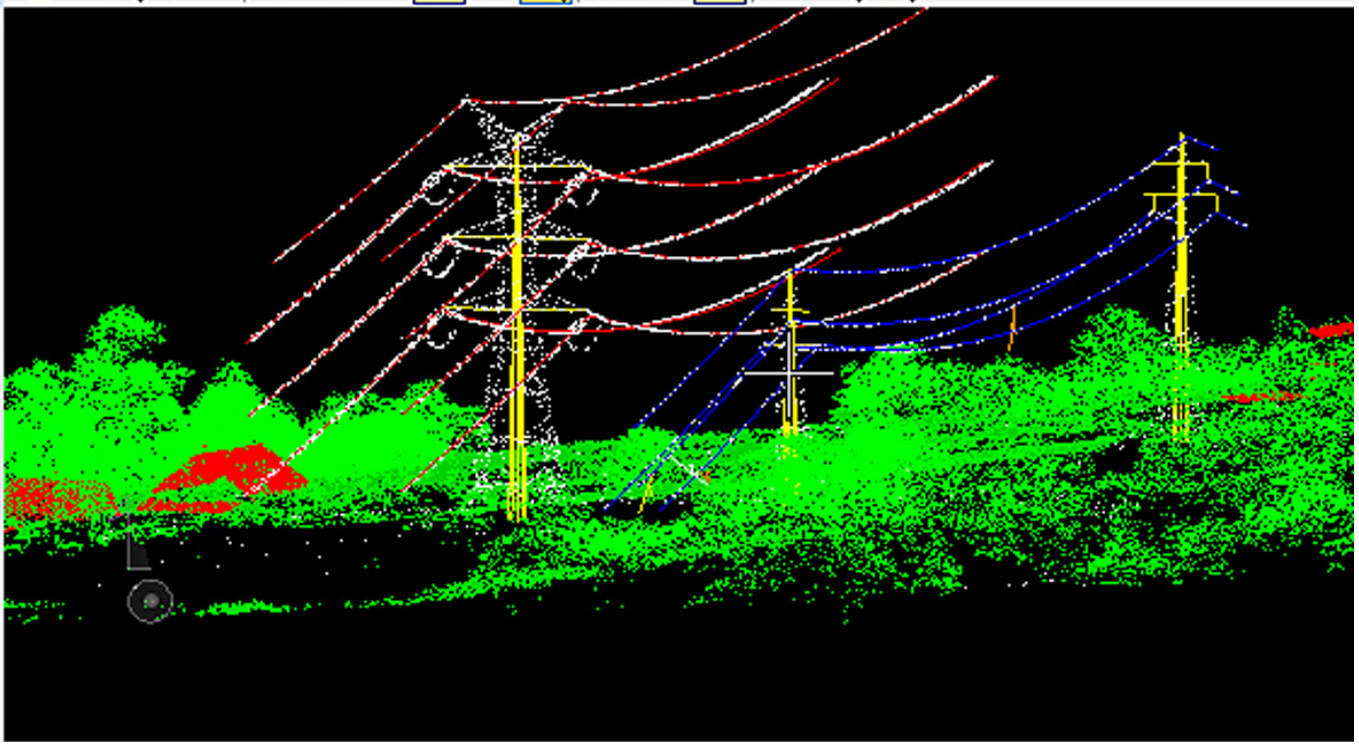

Figure 2. Test object

a)

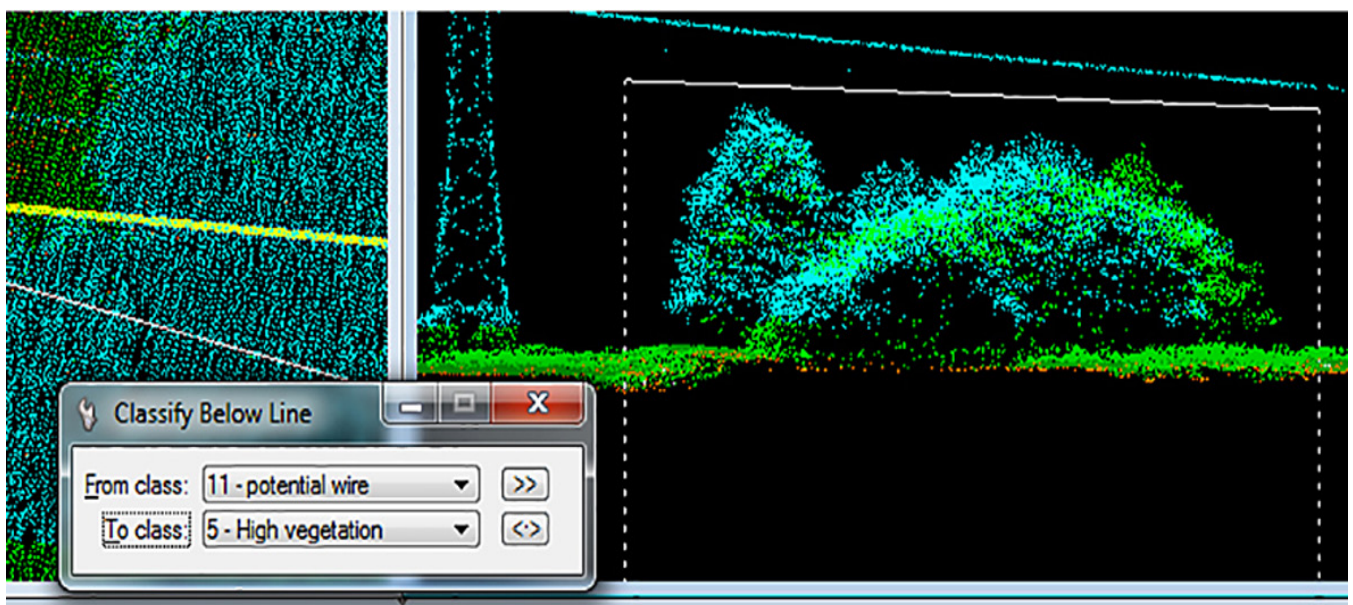

b)

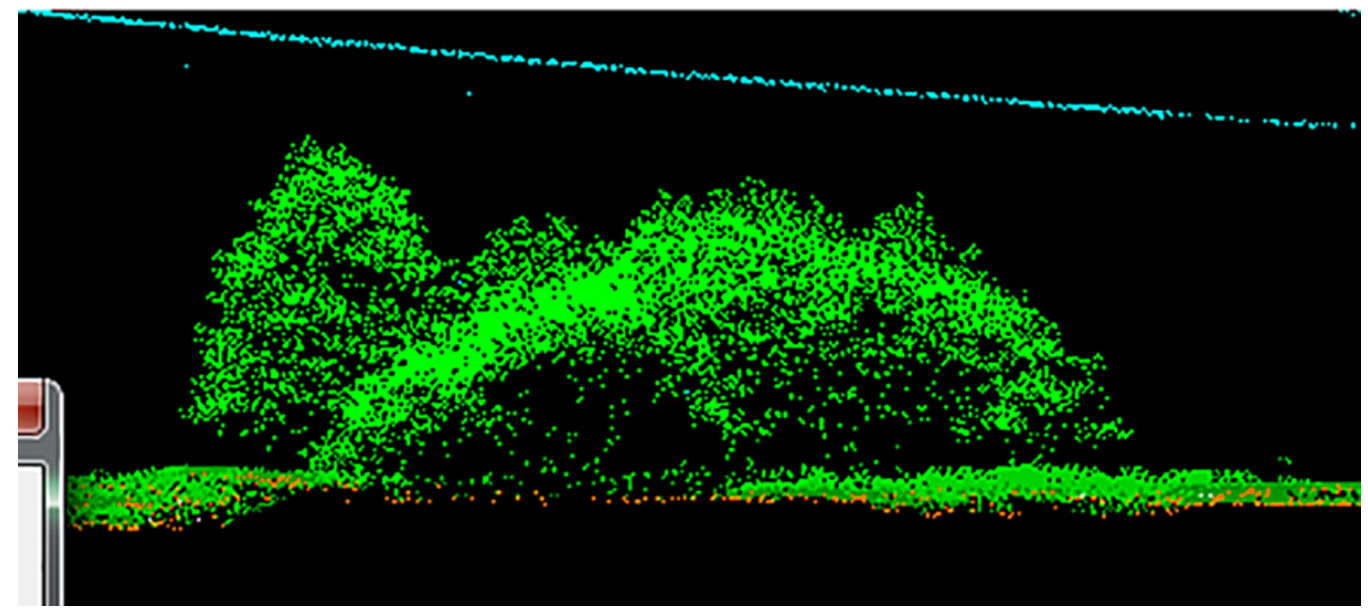

Figure 3. The cloud of points after the classification: a) automatic, b) manual 
ate classes, on which the specific data type will be transferred. The program proposes to use already existing classes named: Ground, Low vegetation, Medium vegetation, High vegetation, Buildings, Low point (Erroneous points, usually located below the ground), Model keypoints (selection of the part of points from the class Ground to provide terrain model) and Default (the base class - level 0). For the purpose of the study, the authors separated the following additional classes:

- towers - points representing energy towers,

- potential wire,

- wire,

- infrastructure.

After classification of the cloud of points, the user draws the vector connecting centers of subsequent poles forming the entire line. It allows subsequently to obtain views of the relevant parts of the line in top views, profiles and cross-sections (Figure 4), so that the process of elaboration goes as smoothly as possible.

Tools of the TerraScan overlay enable very fast, automatic vectorization of overhead wires (Figure 5). In the case of its low effectiveness it is possible to choose semi-automatic or manual method.
During vectorization of poles predefined templates of standard columns that the user creates after their classification are helpful (Figure 6). Very important in the elaboration of power lines is the hazard analysis, enabling detection of objects in dangerously close proximity to the line (eg. trees) and presenting a risk in the event of overturning (Figures 7a and b).

The results of these operations are presented, by separating the dangerous objects in the point cloud or generating the relevant reports (Table 1). This report may provide information for each individual line, which is a great help in the process of maintenance, because it indicates the exact location where triming of the trees or other type of intervention are necessary. It should be noted that the user defines himself in the program search parameters of threats, so that - in line with the applicable standards - to find these objects, which exceed safety limits. In the case when the network of poles is extensive, the tools for the automatic labeling of objects and simple viewing the lines are useful [Mądrzyk 2015].

As a result of work carried out in the Terrasolid program it is possible to make cross-sections of the whole surveyed network in 2D and the cross-sections between the individual towers together with, profiles of the terrain between them (Figure 8).

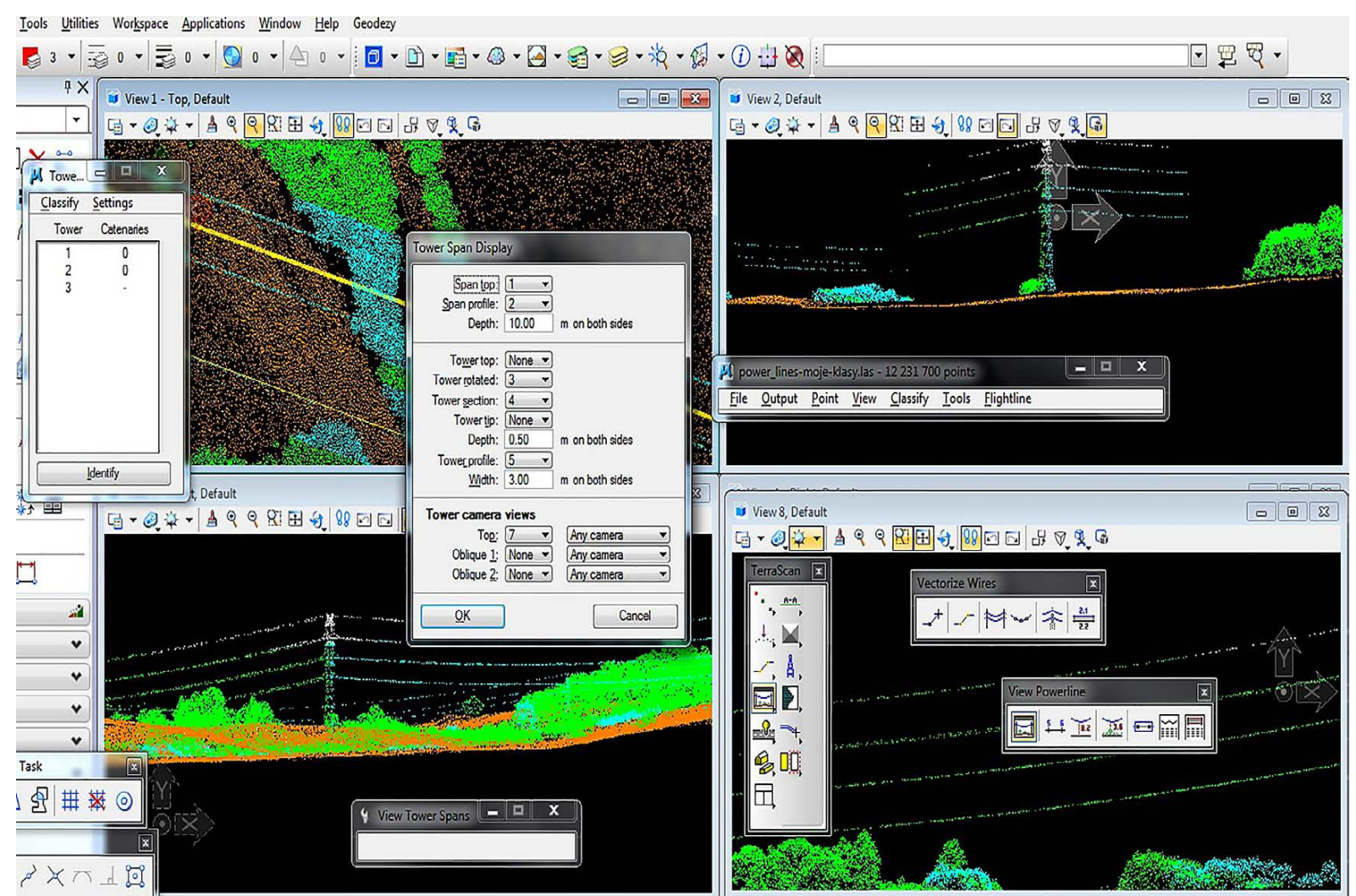

Figure 4. View of the power line in cross-sections and top view 
a)

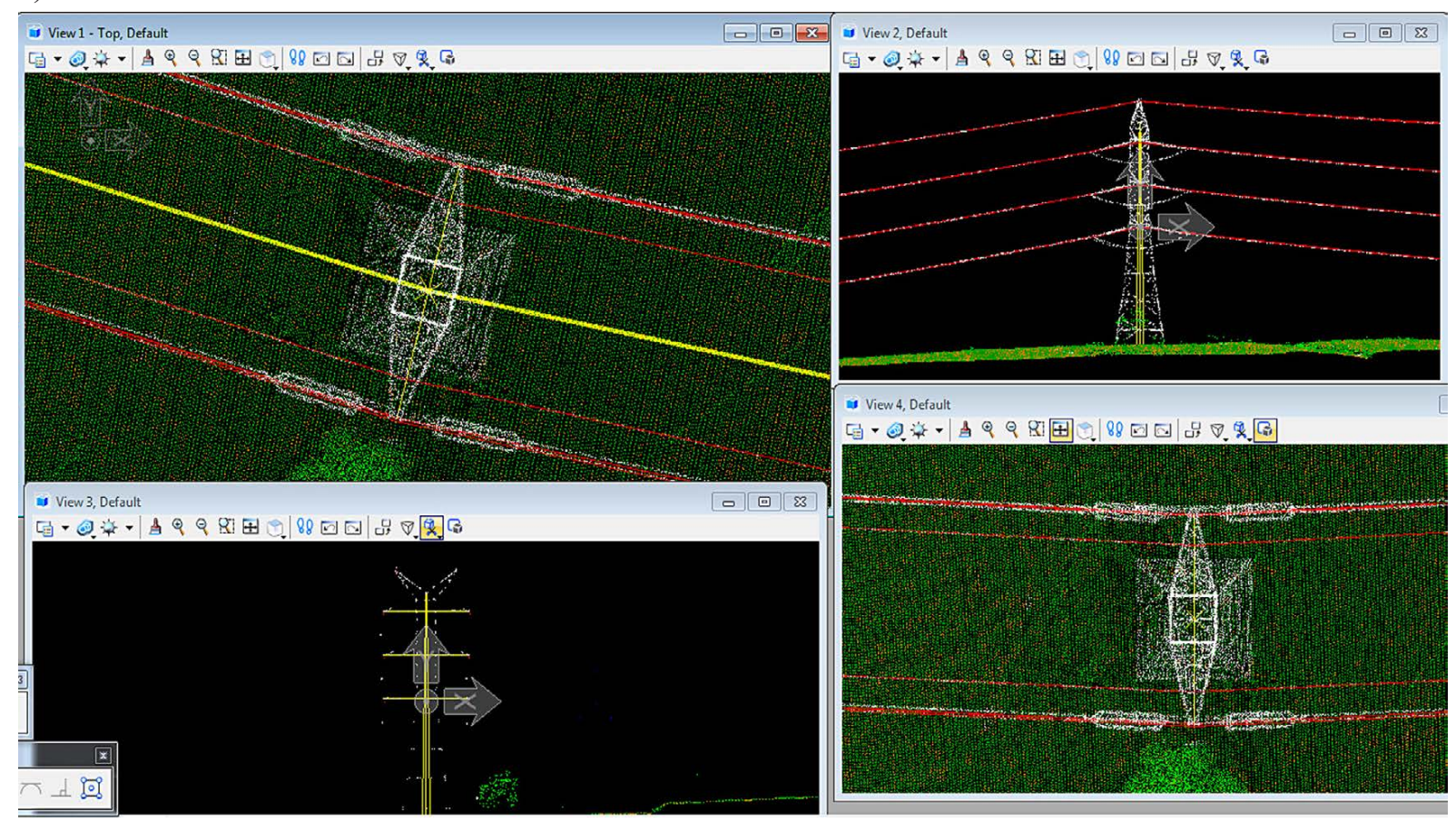

b)

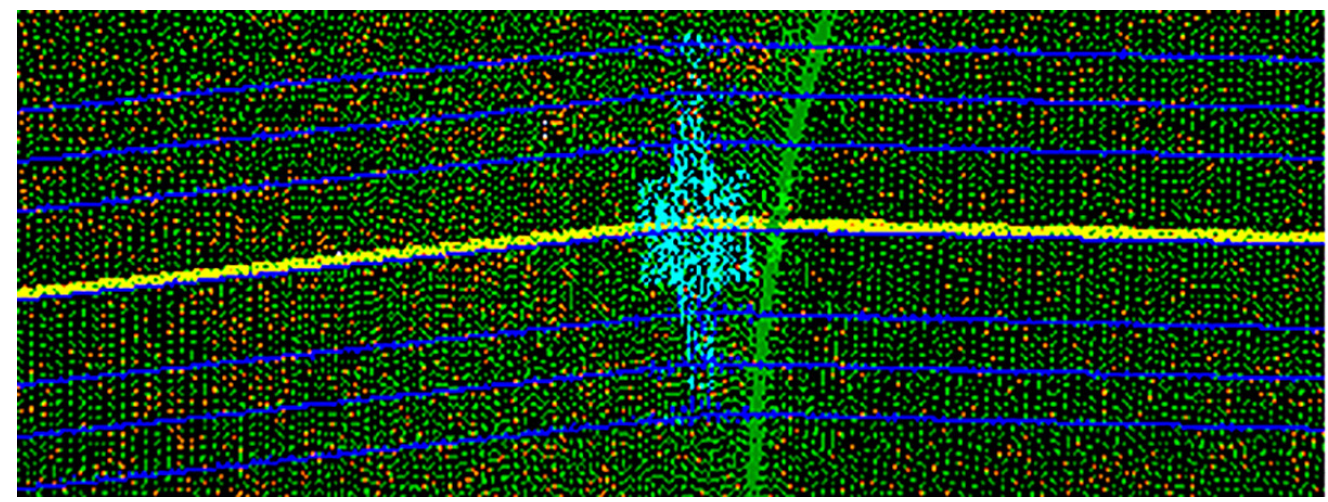

Figure 5. The result of automatic vectorization of cables on the line of a/ high, b / low voltage

a)

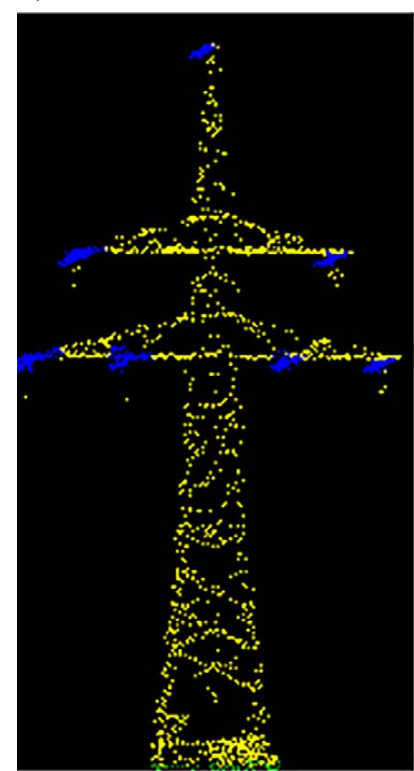

b)



c)

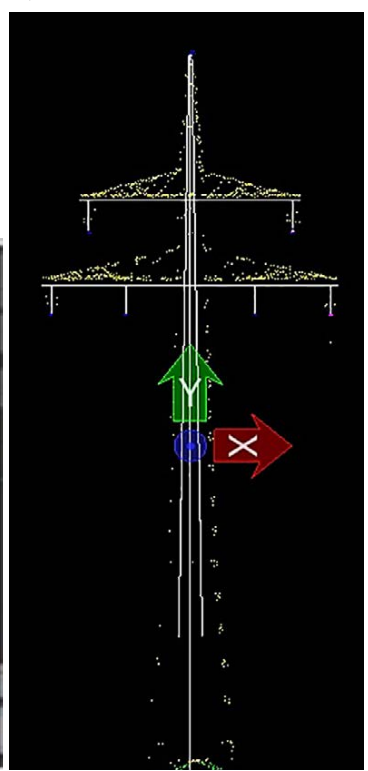

Figure 6. High voltage tower: a) after classification, b) template, c) after vectorization 
a)

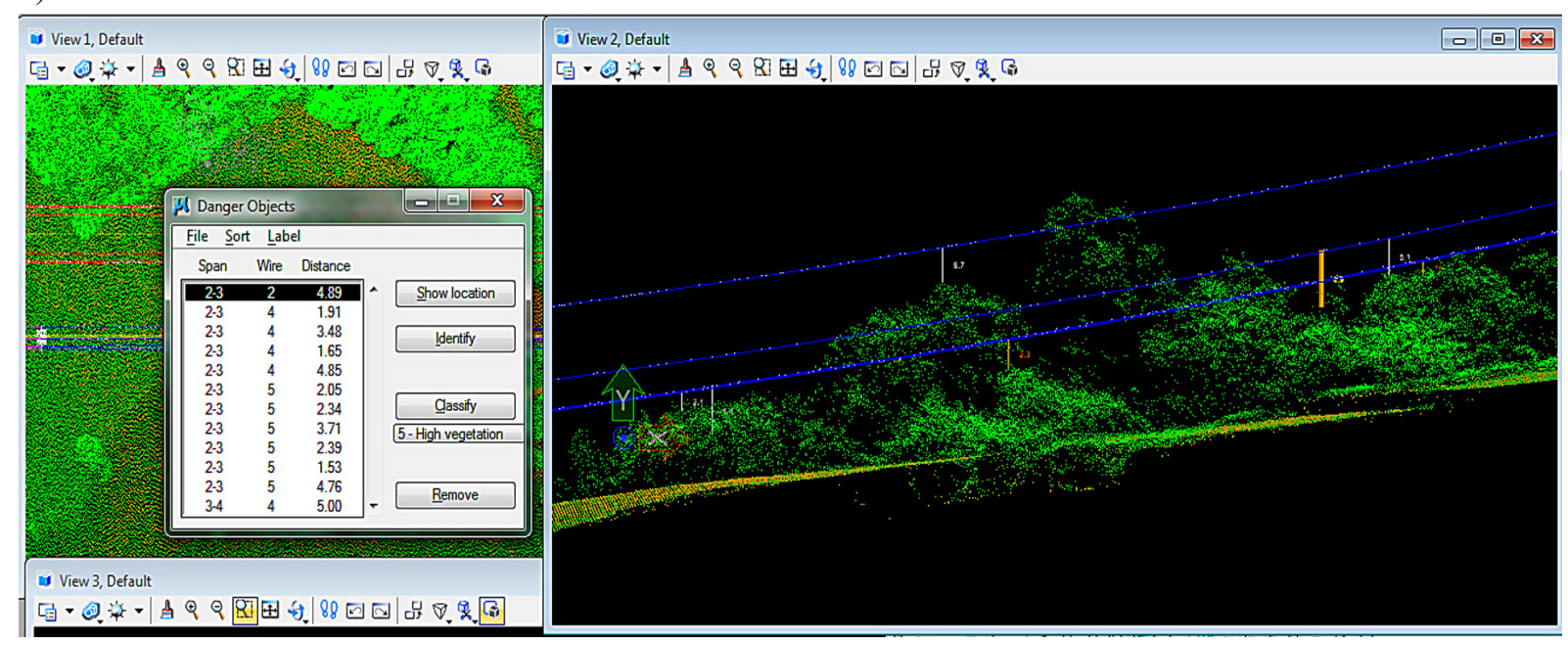

b)

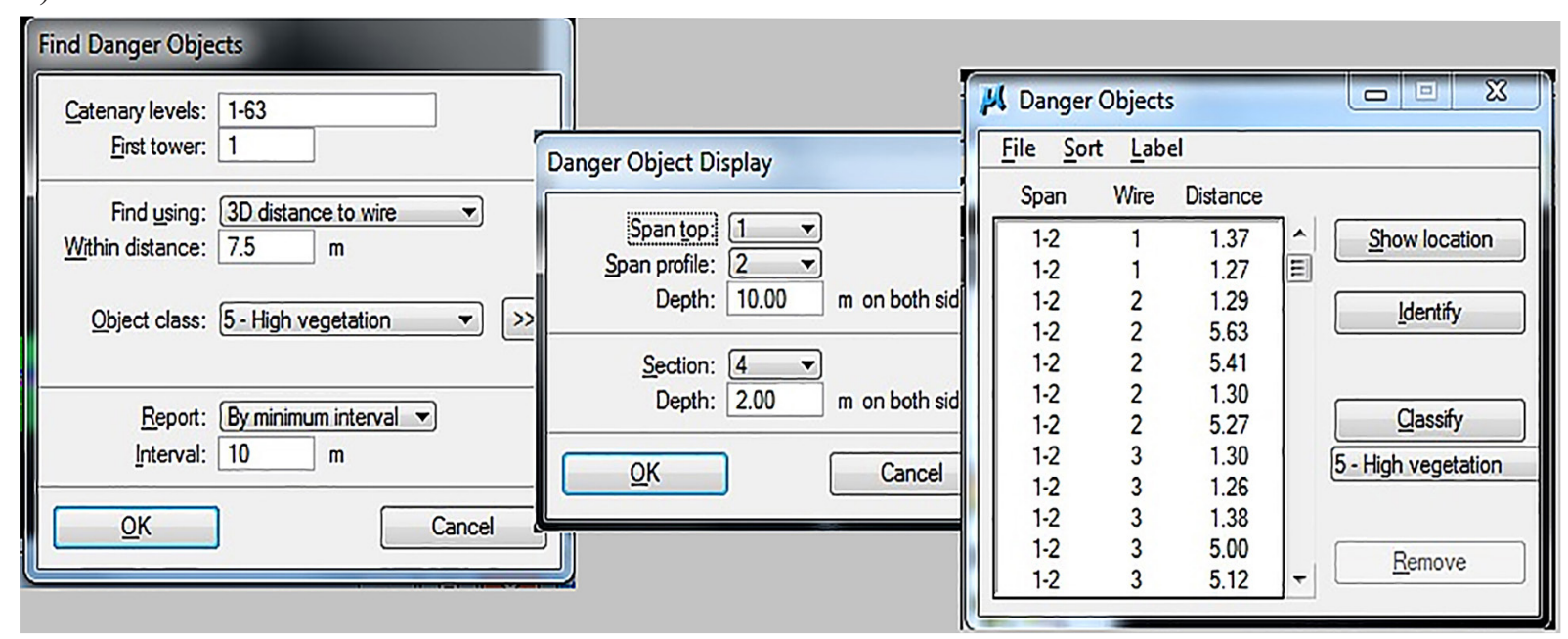

Figure 7. (a) Identification of obstacles and threats,

(b) Dialog Windows of the Find Danger Objects function

Table 1. The result of the report specifying the distance to objects dangerous for the power line

\begin{tabular}{|c|c|c|c|c|c|c|}
\hline Tower & $\begin{array}{c}\text { Distance from the } \\
\text { dangerous objects }\end{array}$ & $X$ & $Y$ & $X^{\prime}$ & $X^{\prime}$ & $Y^{\prime}$ \\
\hline 1 & -5.64 & 9011.59 & 3592.08 & 405.78 & 400.55 & 1315.52 \\
\hline 2 & -4.98 & 9311.52 & 3622.98 & 412.41 & 407.04 & 1506.55 \\
\hline 3 & -4.89 & 9622.58 & 3614.94 & 417.60 & 403.40 & 1510.84 \\
\hline 4 & -5.16 & 10010.36 & 3605.04 & 414.18 & 402.12 & 1467.41 \\
\hline 5 & -4.81 & 10297.09 & 3481.19 & 406.86 & 399.61 & 1324.67 \\
\hline 6 & -4.93 & 10617.69 & 3454.91 & 411.75 & 409.47 & 1335.00 \\
\hline 7 & -4.91 & 10879.12 & 3433.28 & 419.86 & - & - \\
\hline
\end{tabular}

\section{CONCLUSIONS}

Failure-free operation of energy infrastructure devices needs monitoring, and periodic surveying. The data obtained using laser scanning with appropriate density of sampling ensure obtaining accurate information about the geometry of poles, transmission lines and other infrastructure elements as well as objects in the immediate vicinity. Used together with data from photogrammetric methods and thermal imaging it may form the basis of decision making in diagnosing the network. 


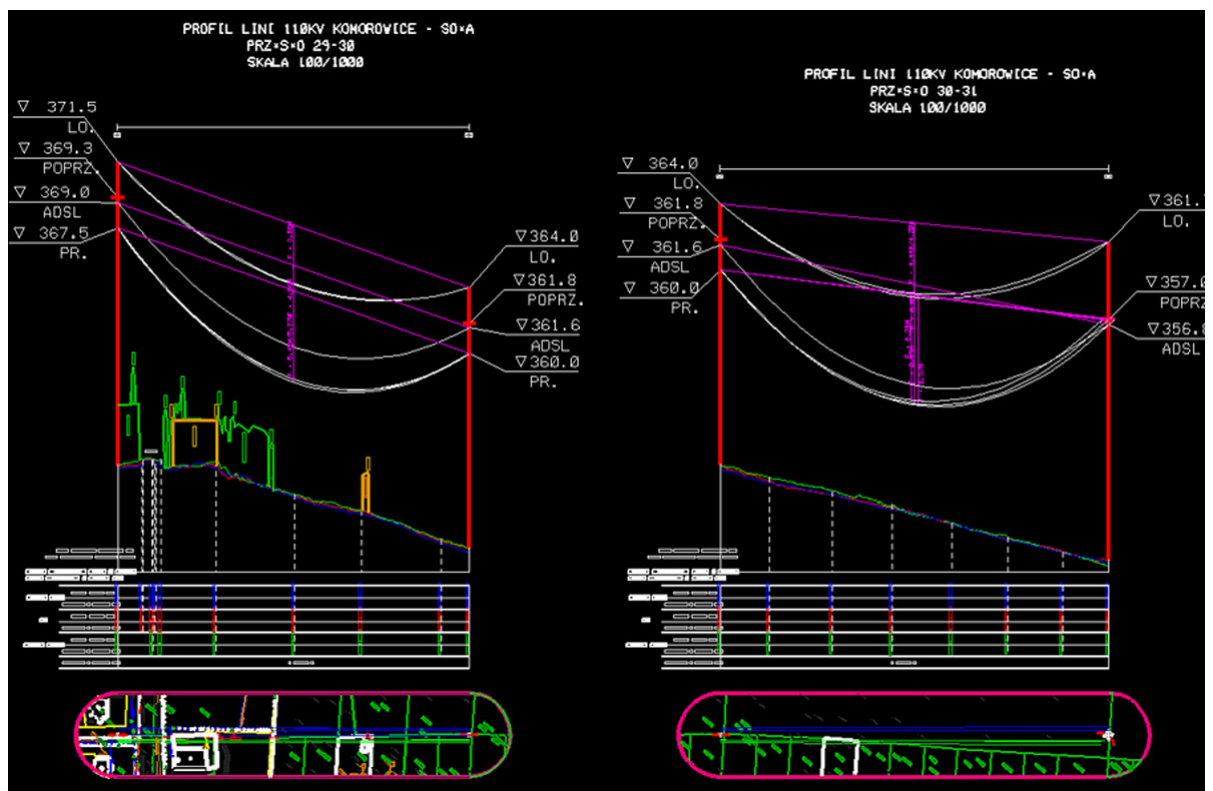

Figure 8. 2D cross-section between any two power poles along with the terrain profile [Biuro Geodezyjne Geo-Proces]

The conducted research allowed to make conclusion, that the cloud of points with a density of 16 points / $\mathrm{m} 2$ provides the ability to perform survey of energy network, nevertheless, automatic vectorization of cables is sometimes difficult (interrupts in the continuity of cables arise, even though the TerraScan overlay has a tool to repair this type of error). Even the cloud with the density of 22 points $/ \mathrm{m}^{2}$ appart from the automatic vectorization required manual adjustments (especially when connecting cables on poles of high or low voltage). Working with a dense cloud of points is obviously easier, but it is not always possible to have as dense data, because they require the implementation of special flights. Due to the fact that the cloud with a density of 22 points $/ \mathrm{m}^{2}$ meets the boundary requirements, included in the sample project, it can be used for the survey of power lines purposes. Laser scanning, however, is currently the best technology, which enables realistic representation of the poles geometry and overhead power lines, and rapid detection and thus the elimination of collisions with vegetation, allows improving the management of the energy network.

\section{REFERENCES}

1. Bęcek K., Gawronek P., Klapa P., Kwoczyńska B., Matuła P., Michałowska K., Mikrut S., Mitka B., Piech I., Makuch M., 2015. Modeling and visualization of $3 \mathrm{D}$ data based on measurements of photogrammetry and laser scanning (in Polish). WSIE Rzeszów.

2. Bitenc M, Lindenbergh R., Khoshelham K., van Waarden A.P. 2011. Evaluation of A LiDAR Land - Bbased Mobile Mapping System for Monitoring Sandy Coasts. Remote Sensing, 3(7), 1472-1491.

3. Dobek J. 2016. The execution of energy network survey using laser Canning (in Polish). Master's thesis. University of Agriculture in Krakow.

4. Figiel M., 2015. Laser scanning, 3D modeling and surveying in industry and construction (in Polish). Modern technologies in industry - Nowoczesne technologie w przemyśle, 1/3a (52), 56-64.

5. Gawronek P. and Mitka B., 2015. The use of terrestrial laser scanning in monitoring of the residential barracks at the site of the former concentration camp Auschwitz II-Birkenau. Geomatics, Landmanagement and Landscape, 3, 53-60, DOI: 10.15576/GLL/2015.3.53.

6. Głowienka E., Jankowicz B., Kwoczyńska B., Kuras P., Michałowska K., Mikrut S., Moskal A., Piech I., Strach M., and Sroka J., 2015. Photogrammetry and the laser scanning in the $3 \mathrm{D}$ modeling (in Polish). WSIE Rzeszów.

7. Gola A., 2015. Airborne laser scanning - practical applications (in Polish). Unpublished.

8. Jwa Y., Sohn G., Kim H.B., 2009. Automatic 3d power line reconstruction using airborne lidar data. Int. Arch. Photogramm. Remote Sens, Vol. XXXVIII, Part 3/W8, 105-110.

9. Kim H.B. and Sohn G. 2010. 3D classification of power-line scene from airborne laser scanning data using random forests. IAPRS, Vol. XXXVIII, Part 3A - Saint-Mandé, France, September 1-3, 126-132. 
10. Liang J., Zhang J., Deng K., Liu Z., Qunshan S., 2011. A new power-line extraction method based on airborne LiDAR point cloud data", Image and Data Fusion (ISIDF), International Symposium, 9-11 Aug., IEEE, DOI: 10.1109/ISIDF.2011.6024293.

11. Mądrzyk J., 2015. The energy in the clouds (in Polish). Geodeta, Laser Scanning, 1(245), pp. 22.

12. McLaughlin R.A., 2006. Extracting transmission lines from airborne LIDAR data. Geoscience and Remote Sensing Letters, IEEE, 3(2), 222-226, DOI: $10.1109 /$ LGRS.2005.863390.

13. Melzer T., Briese C., 2004. Extraction and modeling of power lines from ALS point clouds", Proceeding of 28th Workshop Austrian Association For Pattern Recognition, 17-18 June 2004, Hagenberg, Austria, 47-54.

14. Mikrut S., K. Pyka, and R. Tokarczyk, 2012, „Systems for surveying the railway gauge - an overview and trends (in Polish). Archiwum Fotogrametrii, Kartografii i Teledetekcji, vol. 23, 291-301.

15. Sohn G., Y. Jwa, H.B. Kim 2012. „Automatic power line scene classification and reconstruction using airborne lidar data", ISPRS Annals of the Photo- grammetry, Remote Sensing and Spatial Information Sciences, XXII ISPRS Congress, 25 August 01 September 2012, Vol. I-3, Melbourne, Australia.

16. Soni A., Robson S., and Gleeson B., 2014. Extracting rail track geometry from static terrestrial laser scans for monitoring purposes. The International Archives of the Photogrammetry, Remote Sensing and Spatial Information Sciences, Vol. XL-5, 553557. DOI: 10.5194/isprsarchives-XL-5-553-2014.

17. Stereńczak K., 2009. Airborne laser scanning (LIDAR) in research for the protection of nature (in Polish). Studia i Materiały Centrum Edukacji Przyrodniczo-Leśnej, R. 11, z. 2 (21).

18. Tarek Z., 2002. Airborne laser scanning of the terrain (in Polish). Geodeta, 12, Warszawa.

19. Zhu L. and J. Hyyppa, 2014. Fully-Automated Power Line Extraction from Airborne Laser Scanning Point Clouds in Forest Areas. Remote Sens. 6, 11267-11282. DOI:10.3390/rs61111267.

20. Appendix 1. Report of the performance of the work - GeoProces company Bureau of Surveying.

21. http://www.3deling.pl/2010/10/inwentaryzacjalaserowa-slupow-elektrycznych/ 